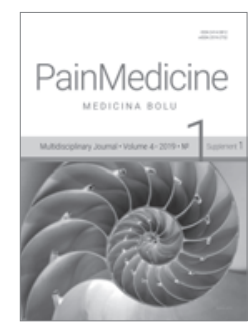

DOI: $10.31636 /$ pmjua.t2.2

\title{
Improvement of complex treatment of patients with osteoarthritis combined with hypertension
}

\author{
Kuznecova L. P., Bondar M. V. \\ State institution "Zaporizhzhya Medical Academy of Postgraduate Education", Zaporizhzhya, Ukraine
}

Actuality: Among the diseases that significantly affect people, osteoarthritis (OA) takes $4^{\text {th }}$ place in women and $8^{\text {th }}$ in men. In both sexes older than 70 years, osteoarthrosis occurs in almost everyone, and in the last decade its prevalence has steadily increased. The social significance of $\mathrm{OA}$ is determined by the increase in disability, especially in older age groups, as well as by a sharp decline in the quality of life for this.

Objective: To evaluate the efficacy of the therapy performed 12 months after initiation of treatment in patients with hypertension (GC) on the background of treatment with meloxicam at a dose of $7.5 \mathrm{mg} /$ day and 80 and $160 \mathrm{mg} /$ day.

Material and methods: under supervision in an outpatient setting, there were 90 patients on the OA 1-2 stages, in combination with GC 2 degree, $2-3$ degrees. The average age of patients with $\mathrm{OA}$ was $64.4 \pm 7.5$ years (the first group), patients with $\mathrm{OA}$ in combination with $\mathrm{GC}-62.13 \pm 8.2$ years (second group), patients with $\mathrm{OA}$ in combination with GC and gastropathy due to admission NSAIDs (third group) $-64.81 \pm 1.3$ years.

Disease duration in patients of the first group - $(9.66 \pm 4.7)$ years, in patients of the second group - $(9.4 \pm 6.0)$ years, in patients of the third group - $(10.4 \pm 5.6)$ years, respectively, the fourth group of comparison contained practically healthy persons.

All patients complained of pain syndrome of varying degrees of severity. Patients in the first group received baseline therapy of meloxi- cam at a dose of $7.5 \mathrm{mg} /$ day; patients in the second and third groups received meloxicam and antihypertensive drug (at a dose of 80 or $160 \mathrm{mg}$ per day). Duration of treatment was 12 months.

Results of the study and their discussion: according to the results, the positive effect of the use of meloxicam has led to a significant decrease in the severity of pain in the first, second and third groups according to the visual analogue scale (VAS): $(27.8 \%, 29.8 \%, 25.4 \%$, $\mathrm{p}<0.05)$ and the Lequesne index $(27.1 \%$ and $30.9 \%, 26.4 \%, \mathrm{p}<0.05)$, respectively.

Conclusions: 1. The tested scheme of treatment of patients with $\mathrm{OA}$ with the use of meloxicam indicates the efficacy and statistically significant reduction of pain syndrome, improvement of the functional state of the musculoskeletal system in patients with $\mathrm{OA}$ as well as with OA in combination with GC. 2. Also, the analgesic and anti-inflammatory effect of meloxicam and its positive effect on the clinical course of OA were revealed: joint pain decreased, functional capacity increased, general well-being and quality of life of patients improved.

Prospects for further research: We consider it expedient to continue prospective surveillance of patients with the aim of further studying of the effect of meloxicam in patients with a comorbid diseases.

Key words: osteoarthritis, hypertension, meloxicam, quality of life.

Conflict of Interest: There is no conflict of interest. 